\title{
Morbidity from excessive intake of high energy fluids: the 'squash drinking syndrome'
}

\author{
J O'B Hourihane, C J Rolles
}

\begin{abstract}
Objective-To identify children suffering morbidity from excessive intake of energy from fluids.

Design-Prospective enrolment of outpatients in a supervised reduction of energy rich fluid intake.

Setting-Outpatient paediatric clinic. Subjects-Eight children (four boys, mean age 20.8 months, mean duration of symptoms seven months) who were referred with non-specific symptoms such as poor appetite, poor behaviour at mealtimes, poor weight gain, and loose stools. Results-All children were able to reduce their intake of energy rich fluids, as prescribed. All children demonstrated an improvement in symptoms and an increase in weight.

Conclusion-A careful dietary history, which includes documentation of fluid intake may identify children whose intake of high energy drinks may be excessive. The pathogenesis, symptoms, and response to treatment of these patients are consistent enough to be regarded as a distinct clinical entity: the 'squash drinking syndrome'.

(Arch Dis Child 1995; 72: 141-143)
\end{abstract}

Keywords: high energy fluids, morbidity.

Dietary preferences are expressed early in life..$^{2}$ Children self regulate their energy intake by compensating at one meal for their high or low intake of energy at the previous meal or snack. ${ }^{3}$ It is therefore theoretically possible for the practice of excessive drinking of fluids that are rich in energy but poor in other nutrients to cause poor appetite at mealtimes and poor weight gain. The high fluid intake may cause loose stools and other non-specific symptoms. ${ }^{4}$

The market for soft drinks and mineral waters is a rapidly expanding area of business growth in the UK. ${ }^{56}$ A study in this hospital has shown that over $70 \%$ of preschool children never drink plain water. ${ }^{7}$ Many of the drinks consumed by this age group are based on fruit products and have a substantial amount of energy per unit volume. Others have shown in studies of adult volunteers and symptomatic children that saccharide and carbohydrate malabsorption can be demonstrated after the consumption of large amounts of fruit juices and that such malabsorption can cause abdominal symptoms and diarrhoea. ${ }^{8-10}$ Carbohydrate and saccharide malabsorption have been postulated as causes of chronic nonspecific diarrhoea of childhood, also known as 'toddler's diarrhoea'. ${ }^{11} 12$

An American study, published recently, has suggested that excessive fruit juice consumption may be significant in certain cases of what the authors have called non-organic failure to thrive. ${ }^{13}$ The authors describe eight children below the 5 th centile for weight. The children's diets were assessed with a three day food record and 24 hour diet recall. Anthropometric measurements were also undertaken. The authors identified excessive intake of apple juice as a contributing factor in the failure of these children to thrive. Exclusion of apple juice caused significant improvements in weight gain.

We have identified prospectively children in a general paediatric outpatient clinic who drink large amounts of fruit juice or squashes and who suffer frequent loose stools and are reported to have poor appetites. This paper tests two hypotheses. Firstly, that the children's appetites may have been poor at mealtimes because of their satisfactory energy intake from another source, that is, from the high energy drinks they consume during the day. This may also have accounted for their reported poor behaviour or general level of non-cooperation with their parents, particularly at mealtimes. Secondly, that by decreasing the amount of energy ingested in the drink fraction of their diet, the children would demonstrate increased dietary intake of carbohydrates and other food groups from other food sources; that this would also decrease their stool frequency and improve their symptoms.

\section{Subjects and methods}

Children were seen in a general paediatric clinic, having been referred for evaluation of their symptoms, which ranged from general irritability and poor appetite - especially at mealtimes - to loose stools and poor weight gain. Other significant diseases were identified or excluded on history and examination.

The amount of fluid ingested was calculated according to the number of feeding bottles or cups of fluid taken during the day (average contents of a feeding bottle being approximately $200 \mathrm{ml}$ ) and the average energy content of each drink was established according to the listed ingredients on proprietary drinks or an equivalent similar drink.

Squash drinks were defined as fruit flavoured drink concentrates diluted with 
Details of patients studied

\begin{tabular}{|c|c|c|c|c|c|c|c|}
\hline \multirow[b]{2}{*}{$\begin{array}{l}\text { Patient } \\
\text { No }\end{array}$} & \multicolumn{4}{|l|}{ At presentation } & \multirow[b]{2}{*}{$\begin{array}{l}\text { Length of } \\
\text { follow up } \\
\text { (months) }\end{array}$} & \multicolumn{2}{|l|}{ After intervention } \\
\hline & Symptoms & $\begin{array}{l}\text { No of } \\
\text { stools/day }\end{array}$ & $\begin{array}{l}\text { Weight } \\
\text { centile }\end{array}$ & $\begin{array}{l}\% R D I^{\star} \text { energy } \\
\text { as squash or } \\
\text { juice }\end{array}$ & & Symptoms & $\begin{array}{l}\text { Change } \\
\text { in weight } \\
\text { centile }\end{array}$ \\
\hline 1 & Polydipsia, diarrhoea & $5-6$ & 3 & 54 & 3 & Improved appetite, normal stools & +4 \\
\hline 2 & Poor appetite & $1-2$ & 40 & 35 & 2 & Improved appetite, normal stools & No change \\
\hline 3 & Poor appetite & $\begin{array}{l}\text { Not } \\
\text { documented }\end{array}$ & 15 & 30 & 6 & Improved appetite, normal stools & +10 \\
\hline 4 & $\begin{array}{l}\text { Poor weight gain, } \\
\text { diarrhoea }\end{array}$ & $2-3$ & 3 & 30 & 6 & Improved appetite & +7 \\
\hline 5 & Poor appetite & $2-3$ & 50 & 54 & 6 & Improved appetite, normal stools & +20 \\
\hline 6 & Diarrhoea & $3-4$ & 15 & 30 & 4 & Improved stools & +25 \\
\hline $7 \dagger$ & Poor appetite & $1-2$ & 10 & 30 & 9 & Improved appetite, normal stools & No change \\
\hline 8 & Diarrhoea, miserable & $2-3$ & 3 & 42 & 2 & $\begin{array}{l}\text { Improved behaviour and appetite, } \\
\text { normal stools }\end{array}$ & No change \\
\hline
\end{tabular}

$\star$ Recommended daily intake. $\nmid$ Known cystic fibrosis.

water before consumption. ${ }^{7}$ The most commonly implicated drink, blackcurrant squash, has approximately $256 \mathrm{~kJ} / 100 \mathrm{ml}$ after dilution. ${ }^{14}$

The parents were asked to decrease the proportion of daily fluid intake that was met by squashes or equivalent drinks. To avoid a punitive setting and to minimise disruption of the child's daily routine, a rigid figure or target volume was avoided. Parents were asked to gradually increase the time interval between drinks given to the child. The reduction in fluid intake was to be gradual and the parents were allowed to introduce similar volumes of low energy drinks or more dilute concentrations of squash drinks. Institution of the study regimen was undertaken on an outpatient basis without professional super vision. Follow up was at routine outpatient appointments, the spacing of which was dictated by clinical considerations rather than study design.

Verbal parental consent was obtained for participation in this study.

\section{Results}

Eight children (four boys) were identified prospectively in a general paediatric clinic over a one year period, from October 1992 to October 1993. The children were identified consecutively and no child whose symptoms could not be attributed to another cause was excluded. No child had been referred specifically with polydipsia. The mean age was $20 \cdot 8$ months, plus or minus 6 months, and the mean duration of symptoms was seven months, plus or minus 5.9 months.

Routine history and examination revealed no other significant illness, apart from the patient whose cystic fibrosis was already identified. A careful dietary history, including a history of daily fluid intake, was taken.

Patients 1, 4, and 5 (see table) were found to be drinking more than 1.5 litres of fluid per day, only a small proportion of which was milk. All patients were found to be ingesting over $30 \%$ of their recommended daily energy intake from fluids other than milk.

Symptoms varied from refusal to sit at table at mealtimes and irritability to loose stools and poor weight gain (see table). These children did not appear to be habitual drinkers and none was in the habit of waking at night for drinks. Breakfast was consistently identified as the meal at which the children ate best. There were no features of malabsorption, such as steatorrhoea and the children appeared to be in otherwise excellent health.

The first few days of the altered drinking regimen were often difficult for the parents with the children having tantrums and behaving badly. Eventually, after a few days, all parents managed to alter their children's drinking habits, although to varying degrees. All parents reported improvements in the presenting symptoms. All children gained weight.

\section{Discussion}

Careful history taking, which included careful documentation of fluid intake, identified children who received a large proportion of their recommended daily intake of energy from 'empty calories', largely from sugary drinks. It was notable that the meal at which there was least parent-child conflict was breakfast. This may reflect the long overnight period the child spent without a drink, causing hunger at breakfast time. Even in the presence of other significant disease, for instance cystic fibrosis, alteration of the child's drinking pattern caused significant improvements in symptoms and weight gain without recourse to extensive investigations.

The children in this study group were slightly younger than the community based group described elsewhere, which demonstrated that water drinking is less prevalent than was previously reported. ${ }^{7}$ We suggest that the children have been conditioned early in life to sweet drinks whose only nutritional advantage is their energy content. An excessive intake of energy from non-food sources may be associated with a wide range of symptoms. This non-nutritious intake of energy (that we have called energy substrate substitution) may decrease appetite, disrupt the hunger-mealsatiety cycle, and cause failure to gain weight. In addition the constituents of the fruit drinks may be laxative.

It is possible that this group of infants represents a variant of toddler's diarrhoea or, conversely, that some children who have been diagnosed as having toddler's diarrhoea 
were actually cases of the 'squash drinking syndrome'. A careful history, which includes more detailed inquiry into fluid intake, may reveal such cases of squash drinking syndrome.

We would suggest that the typical features of the syndrome are as follows:

(1) A child demonstrates poor appetite (or reluctance to eat) at mealtimes. Breakfast is typically the child's best meal.

(2) The child has normal levels of activity and energy.

(3) More than $30 \%$ of the recommended daily intake of energy is taken from drinks other than milk.

(4) The child may have loose stools.

(5) The above features resolve or improve with the reduction of energy taken in drinks, either by replacement with water or drinks of lower energy content.

We suggest further that children who show such typical features merit a trial of dietary adjustment before other more invasive and expensive tests are undertaken.

This group of British children differs in some respects from the group described by Smith and Lifschitz. ${ }^{13}$ Our group did not all demonstrate weights below the 5 th centile at presentation and were not all failing to thrive. The American children appeared to consume apple juice, undiluted, whereas our patients had a more typical British drink, squash. The effect of apple juice and squash may be the same ultimately - what we have called energy substrate substitution and the Americans 'displacement of calorie and nutrient dense foods'. ${ }^{13}$ Smith and Lifschitz comment that parental dietary beliefs may have affected the diets of the children they studied. We would suggest that it is this specific substitute energy substrate (in this case high energy fluids) that has caused the symptoms and clinical signs rather than the parental belief.

We deliberately set out to follow up these children without investigating them extensively. A simple dietary intervention, based on careful history taking, had definite subjective and objective results, without recourse to breath hydrogen testing, anthropometric testing, or formal dietary records. Undoubtedly, some children will require such tests. We feel, however, that a therapeutic trial of reduction of intake of high energy fluids is justifiable before such investigations are undertaken.

The financial consequences of a decrease in squash drinking may be substantial for a family, especially as children are targeted to consume flavoured drinks that lead them, to a degree, to be loyal to a brand or type of drink later in childhood and adult life. ${ }^{12}$

In practice, changing a child's drinking habits may be very disruptive for a family, especially in the short term. We would suggest a similar effect may be obtainable from a switch to low energy drinks of similar flavour and the gradual introduction of more dilute drinks. Our advice to parents was deliberately non-prescriptive and intervention by medical staff was kept to a minimum that parents could expect, that is at routine outpatient appointments.

\section{Conclusion}

This work suggests that a careful dietary history, including full fluids history, may help identify children with a simple imbalance of energy source that causes significant symptoms and signs. Such children, irrespective of other pathology, may be helped by non-coercive alteration of their drinking habits. The change of drink type may have substantial benefits to the children and the family as children are increasingly a target sector for marketing of drinks that may not be of dietary benefit to them if taken in excess.

1 Vobecky JS, Vobecky J, Omers PP, et al. Food and nutrient intake of infants for the first fifteen months of life. intake of infants for the first fifteen mont
Nutrition Reports International 1980; 22: 571 .

2 Michelson O. Prevention and treatment of obesity. In: Schemm R, ed. Nutrition, physiology and obesity. Florida: CRC Press, 1980.

3 Shea S, Stein AD, Basch CE, Contento IR, Zybert P. Variability and self regulation of energy intake in young children in their every day environment. Pediatrics 1990; 90: 542-6.

4 Green HL, Ghishan FK. Excessive fluid intake as a cause of chronic diarrhoea in young children. $\mathcal{F}$ Pediatr 1983; 102: 836-40.

5 Hall R. The market for bottled water. Soft Drinks Management International. London: British Soft Drinks

Association, Dec 1991: 19-21.
6 Fortuna E. Unrivalled growth for natural mineral waters. Soft Drinks Management International. London: British Soft Drinks Association, Sept 1993: 25-60.

7 Petter LPM, Hourihane JO'B, Rolles CJ. Is water out of vogue? A survey of the drinking habits of 2-7 year olds. Arch Dis Child 1995; 72: 137-40.

8 Hyams JS. Sorbitol intolerance: an unappreciated cause of functional gastrointestinal complaints. Gastroenterology 1983; 84: 30-3.

9 Hyams JS. Chronic abdominal pain caused by sorbitol malabsorption. F Pediatr 1982; 100: 772-3.

10 Hyams JS, Leichtner AM. Apple juice: an unappreciated cause of chronic diarrhoea. Am $\mathcal{F}$ Dis Child 1985; 139: 503-5.

11 Lifshitz F, Ament ME. Role of juice carbohydrate malabsorption in chronic non-specific diarrhoea in children. $\mathcal{f}$ Pediatr 1992; 120: 825-9.

12 Treem WR. Chronic nonspecific diarrhoea of childhood. Clin Pediatr (Phila) 1992; 31: 413-20.

13 Smith MM, Lifschitz F. Excess fruit juice consumption as a contributing factor in non-organic failure to thrive. Pediatrics 1994; 93: 438-43.

14 Holland B, Welch AA, Unwin ID, Buss DH, Paul AA, Southgate DAT. McCance and Widdowson's the composition of foods. 5th Ed. Cambridge: The Royal Society of Chemistry and The Ministry of Agriculture, Fisheries and
Food, 1991. 